\title{
Treating Neurovisual Deficits and Spatial Neglect
}

\author{
Georg Kerkhoff, Gilles Rode, and Stephanie Clarke
}

\section{Neurovisual Disorders After Brain Damage}

Neurovisual disorders are frequent function losses after brain damage and occur in about $20-50 \%$ of the patients with cerebrovascular disorders (Rowe et al. 2009). In stroke patients $>65$ years, the incidence rises to 40-60\% (Suchoff et al. 2008). Homonymous visual field defects (further abbreviated as VFDs) are present in 20-50\% of all neurological patients with stroke (Kerkhoff 1999; Rowe et al. 2009) and also occur frequently in patients with traumatic brain injury, TBI (Kerkhoff 1999). Visual field sparing is $<5^{\circ}$ on the blind side in $70 \%$ of stroke cases with VFDs (Zihl 2011; Kerkhoff 1999). Spontaneous field recovery is present in the first 2-3 months post-lesion in up to $40 \%$ of the patients with a stable aetiology such as stroke (Zhang et al. 2006). After 6 months post-lesion, spontaneous recovery is extremely unlikely (Zhang et al. 2006; Zihl 2011).

Patients with VFDs present three types of associated deficits: visual exploration (or scanning) deficits, hemianopic alexia, and visuospatial deficits. With respect to the first point, patients show a time-consuming, inefficient visual search due to loss of overview and unsystematic search strategies. They make many, small amplitude staircase saccades in the blind hemifield and omit targets in the blind field (Kerkhoff

\footnotetext{
G. Kerkhoff $(\bowtie)$

Clinical Neuropsychology \& Neuropsychological Outpatient Unit, Saarland University, Saarbruecken, Germany

e-mail: kerkhoff@mx.uni-saarland.de

G. Rode

Department of Rehabilitation, Centre Hospitalier Universitaire de Lyon, Lyon, France e-mail: gilles.rode@chu-lyon.fr

S. Clarke

Service de neuropsychologie et de neuroréhabilitation, Centre Hospitalier Universitaire Vaudois (CHUV), Lausanne, Switzerland

e-mail: Stephanie.Clarke@chuv.ch 
et al. 1992a, 1994; Pambakian et al. 2004; Machner et al. 2009). Second, the central visual field ( $\pm 5^{\circ}$ around the fovea) is crucial for reading because only here visual acuity and form recognition are sufficient for letter recognition ("perceptual reading window"). Hence, slow reading with errors is evident in VFD patients with a field sparing $<5^{\circ}$ on the blind side of the field, as there is a monotonic relationship between the degrees of visual field sparing on the blind side and reading speed (Kerkhoff 1999). Third, the patient's feeling of the subjective visual straight ahead in space or his/her subjective midline in bisecting horizontal lines and objects is shifted towards the blind field. This shift is horizontally in left/right VFDs, vertically in altitudinal upper/lower VFDs, and oblique in quadrantic VFDs and occurs in $90 \%$ of the patients (Kerkhoff 1993; Barton and Black 1998; Kuhn; for review see Kerkhoff and Schenk 2011). This spatial shift is also evident in pointing (Hesse et al. 2012) and in daily life (walking through doorways, halving a bread).

Importantly, all three types of visual deficits in VFDs are relevant for daily life: the visual exploration disorder leads to problems in finding objects, persons, or vehicles or colliding with them, especially on the blind side. The reading deficit impairs virtually all activities where reading of letters, numbers, or other symbols is required, and the spatial midline shift affects pointing, walking, halving objects, or drawing. The International Classification of Functioning (ICF) serves as a reference for holistically understanding the different aspects of a pathology (WHO 2001). Figure 1 gives an overview of different neurovisual disorders in the framework of the ICF.

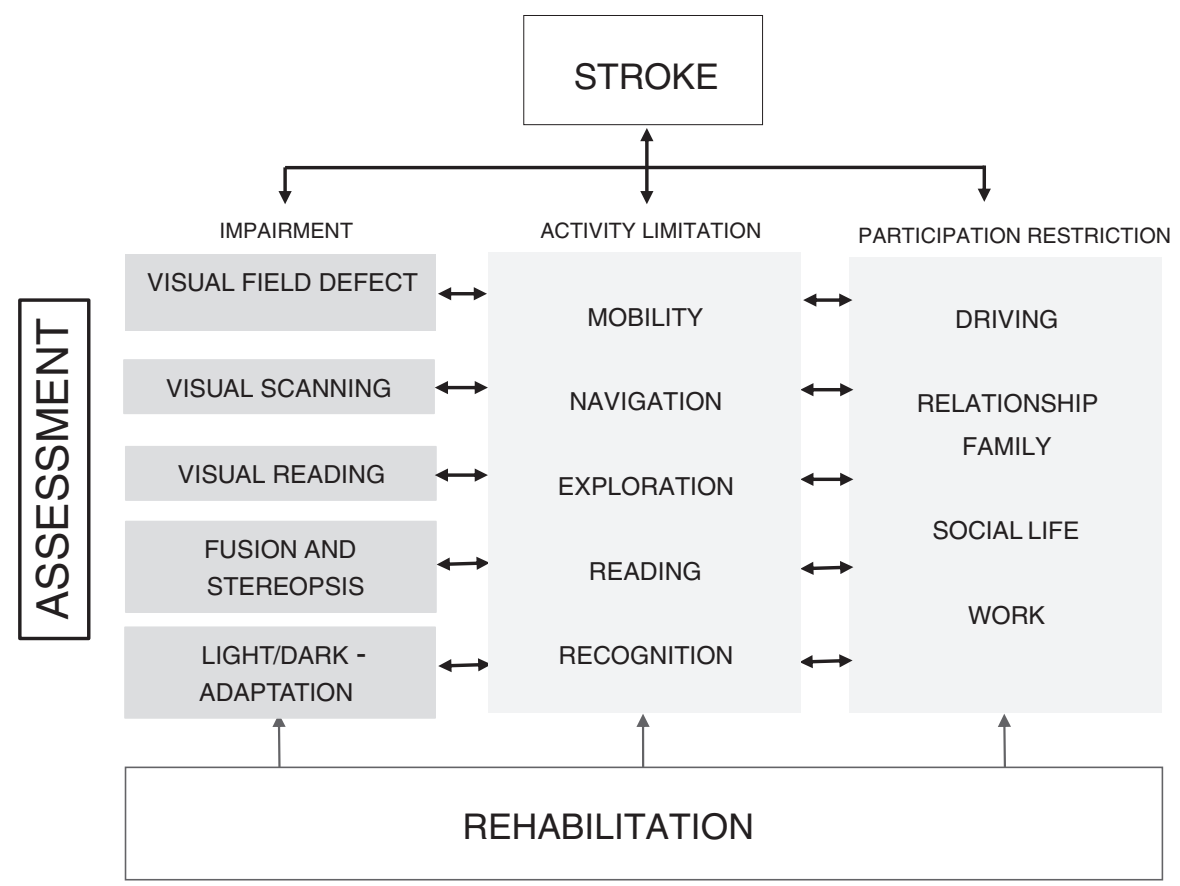

Fig. 1 Neurovisual deficits in the ICF-Framework 
Apart from homonymous VFDs and the associated impairments in reading, visual exploration, and spatial midline perception, further low-level (impaired visual acuity and contrast sensitivity, stereopsis and binocular fusion, colour perception, light-dark adaptation, motion perception) as well as high-level (visual object and face agnosia, spatial-perceptual disorders) neurovisual disorders are often found after brain damage (for review see Schaadt and Kerkhoff 2016). Consequently, routine screening of the various types of visual deficits is necessary both for diagnosis and rehabilitation planning.

\subsection{Assessment of Neurovisual Disorders}

Before starting any assessments, a systematic anamnesis of the most frequently encountered neurovisual deficits should be performed (Table 1) as it reduces the clinician's risk to overlook relevant disorders. Patients with intact awareness can

Table 1 Schema for the anamnesis of neurovisual disorders after acquired brain lesions

\begin{tabular}{|c|c|}
\hline Question & Purpose of question, underlying disorder, tests \\
\hline 1. ... any changes in vision ...? & - Awareness of deficits? Case history? \\
\hline 2. ... diplopia ....? transiently/permanently? & $\begin{array}{l}\text { - Type of gaze palsy? If transient: fusional } \\
\text { disorder? Impaired stereopsis? }\end{array}$ \\
\hline $\begin{array}{l}\text { 3. ... reading problems ...? ... syllables/ } \\
\text { words missing, change of line, reduced } \\
\text { reading span ...? }\end{array}$ & $\begin{array}{l}\text { - Hemianopic alexia due to VFD? Differential } \\
\text { diagnosis of neglect dyslexia, aphasic alexia, } \\
\text { pure alexia, or Balint-Holmes syndrome }\end{array}$ \\
\hline $\begin{array}{l}\text { 4. ... problems in estimating depth on a } \\
\text { staircase ...? ... reaching with your } \\
\text { unimpaired hand for a cup, hand, door } \\
\text { handle ...? }\end{array}$ & $\begin{array}{l}\text { - Depth perception? Optic ataxia? Reduced } \\
\text { acuity/contrast sensitivity? }\end{array}$ \\
\hline $\begin{array}{l}\text { 5. ... bumping into obstacles ...? ... failure } \\
\text { to notice persons ...? at which side? }\end{array}$ & $\begin{array}{l}\text { - Visual exploration deficits due to VFD/ } \\
\text { Neglect/Balint-Holmes syndrome? }\end{array}$ \\
\hline $\begin{array}{l}\text { 6. ... blinding after exposure to bright } \\
\text { light ...? }\end{array}$ & - Foveal photopic adaptation? \\
\hline $\begin{array}{l}\text { 7. ... dark vision ....? ... that you need } \\
\text { more light for reading ...? }\end{array}$ & - Foveal scotopic adaptation? \\
\hline $\begin{array}{l}\text { 8. ... blurred vision ....? transiently/ } \\
\text { permanently? }\end{array}$ & - Contrast sensitivity? Visual Acuity? Fusion? \\
\hline $\begin{array}{l}\text { 9. } \ldots \text { that colours look darker, paler, less } \\
\text { saturated ...? }\end{array}$ & $\begin{array}{l}\text { - } \begin{array}{l}\text { Colour hue discrimination? Impaired } \\
\text { contrast sensitivity? }\end{array}\end{array}$ \\
\hline 10. ... that faces look darker, paler, unfamiliar ...? & - Face discrimination/recognition disorders? \\
\hline 11. ... problems in recognizing objects ...? & - Object discrimination/recognition disorders? \\
\hline $\begin{array}{l}\text { 12. ... problems in finding your way in } \\
\text { familiar/unfamiliar environments ...? }\end{array}$ & $\begin{array}{l}\text { - Topographic orientation deficits? Spatial } \\
\text { memory? }\end{array}$ \\
\hline $\begin{array}{l}\text { 13. ... visual hallucinations (stars, dots, } \\
\text { lines, fog, faces, objects ...) or illusions } \\
\text { (distorted objects, faces ...) ...? }\end{array}$ & $\begin{array}{l}\text { - Simple or complex visual hallucinations, } \\
\text { illusions? Awareness about illusory } \\
\text { character? }\end{array}$ \\
\hline
\end{tabular}

Indent the questions in the table into the following phrase: "Did you experience ... since your brain lesion?" (Based on Neumann et al. 2016). On the right side, the purpose of each question is illustrated and the putative underlying disorder and tests to be performed. VFD: homonymous visual field defect 
easily and quickly (<10 min) be questioned with this simple questionnaire, responses to which prove clinically useful and reliable in $95 \%$ of cases (Neumann et al. 2016). Moreover, this anamnesis leads the clinician to appropriate diagnostic tests and subsequent treatments.

Subsequently, quantitative tests should be performed. As VFDs are the most frequent neurovisual deficits after brain damage, a quantitative perimetry (using a bowl perimeter) or at least campimetry (on a flat monitor or test plate) should be performed in every case (for details see Biousse and Newman 2009). If time is too short for an apparative perimetry/campimetry, finger perimetry should be performed, by using a coloured pen as a target for identification along the different meridians. This quick ( $3 \mathrm{~min}$ ) procedure increases the sensitivity of detecting scotomas by some $20 \%$ when compared with using only the examiners fingers (Kerr et al. 2010). After the visual field test, reading should be tested with a standardized reading test (i.e. Radner test), visual scanning, or search with a standardized test, and finally, horizontal and vertical line bisection should be performed to detect a subjective visual midline shift (see Lezak, Howieson, Bigler and Tranel 2004 for appropriate tests). Further, neurovisual tests may be necessary depending on the type of deficit and the patient's subjective complaints. These may include tests of visual object and face recognition, as well as naming tests, in order to disentangle visual object recognition from deficits in object naming (see Schaadt and Kerkhoff 2016, for overview). For these purposes, the VOSP (Visual Object and Space Perception Battery) is suitable to test visual object recognition, the Facial Recognition Test for face perception, and several naming tests including the Boston Naming Test to evaluate naming performance (see Lezak, Howieson, Bigler and Tranel 2004 for further details to these tests and references).

\subsection{Therapy of Neurovisual Disorders}

The recommendations for treatments given below are based on results from individual trials as stated below, a Cochrane review (Pollock et al. 2012), and two further reviews of that topic (Trauzettel-Klosinski 2011; De Haan et al. 2014).

As spontaneous visual field recovery is very limited during or absent after the first 3-6 months post-stroke (Zhang et al. 2006), the vast majority of VFD patients will suffer from a permanent and stable VFD.

The Cochrane meta-analysis demonstrated that scanning training is more effective than control or placebo at improving reading ability (3 studies, 129 participants; standardized mean difference (SMD) $0.79,95 \%$ confidence interval (CI) 0.29-1.29) and visual scanning (3 studies, 129 participants; SMD 1.14, 95\% CI 0.29-2.00) but that scanning may not improve visual field outcomes (2 studies, 110 participants; MD $-0.73,95 \% \mathrm{CI}-3.18$ to 1.72 ). The review reached the following conclusions: "There is limited evidence that supports the use of compensatory scanning training for patients with visual field defects (and possibly coexisting visual neglect) to improve visual field, scanning, and reading outcomes. There is insufficient evidence to reach a conclusion about the impact of compensatory scanning training on 
functional activities of daily living. There is insufficient evidence to reach generalized conclusions about the benefits of restitutive or substitutive interventions for patients with visual field defects after stroke". For clarity, we will deal with these treatments in separate sections below in more detail.

\subsubsection{Saccadic Compensation (or Scanning) Training}

Saccadic compensation training (SCT or scanning) aims at improving the quick and safe visual overview over a visual scene, despite the fact that the field cut will persist in the vast majority of patients with VFDs. This is reached by enlarging saccade amplitude and reducing saccadic reaction time when looking to the blind portion of the visual field (Kerkhoff et al. 1992a, b, 1994). Several observational and smaller randomized controlled trials (RCTs) (Kerkhoff et al. 1992a, b, 1994; Roth et al. 2009; Lane et al. 2010; Mödden et al. 2012; De Haan et al. 2015; Aimola et al. 2014) indicated that these procedures improve visual scanning in VFDs; the effects might, however, at least partially be related to attention training effects (e.g. Lane et al. 2010), which in itself might also be an effective treatment strategy. Moreover, it can be assumed that visual scanning training almost always includes attentive elements, otherwise the training cannot be performed. Moreover, improvements in ADLs were inconsistently shown, e.g. on mobility (De Haan et al. 2015). A cross-modal (visual-auditory) variant of this training is also effective in improving scanning and reading in hemianopia (Keller and Lefin-Rank 2010). Here, visual and auditory targets are presented time-locked in identical locations of the visual field, and the patient has to look to them. This training induces similar improvements as conventional visual scanning training but requires additional technical facilities.

\subsubsection{Hemianopic Reading Training}

Hemianopic reading training entails the oculomotor compensation of the reading deficit that arises from the loss of parafoveal visual field regions that have a sufficiently good visual acuity in order to identify letters and syllables. Most effective strategies of reading training for hemianopic alexia have used an "optokinetic" approach. Here, letters, syllables, words, and numbers are presented in a single text line which float from the right to the left side on a computer screen, while the patient is instructed to read the words in the middle of the screen. The moving character of the words induces pursuit eye movements to the side of motion and an optokinetic nystagmus to the opposite side (Kerkhoff et al. 1992a, b). At least four more or less well-controlled treatment studies have shown that this kind of treatment significantly improves reading speed, reduces reading errors, and reduces the number of eye fixations during reading (Kerkhoff et al. 1992a, b; Zihl 1995; Spitzyna et al. 2007; Schuett et al. 2008; see review in Schuett 2009). The mean improvement of reading speed when expressed in words per minutes (WPM) read was 38.4 WPM after this type of reading training (see Kerkhoff 2010, page 85). In cultures reading from left to right the motion should be from right to left, in those reading from right to left the motion should be left to right, and in those reading from top to bottom the motion should move upwards. 


\subsubsection{Compensatory or Restorative Visual Field Training?}

In recent years, restorative visual field training has been revived after publication of apparently advantageous results following new training procedures (Kasten et al. 1998). However, numerous subsequent replication studies have failed to find significant visual field enlargements (Nelles et al. 2001; Pambakian et al. 2004; Schreiber et al. 2006; Roth et al. 2009), or found only minimal visual field increases ( $1^{\circ}, \mathrm{cf}$. Mödden et al. 2012). In our view, restorative field training is only promising when lesions are incomplete, and a high degree of residual visual capacities (light, motion, form, or colour perception) is preserved in specific regions of the scotoma (Kerkhoff 2000; Bouwmeester et al. 2007). This residual vision is only present in some 5\% of VFD patients and is lacking in the majority of patients. Moreover, restorative visual field training induces only very small or no visual field increases $\left(\sim 1^{\circ}\right)$ and improves visual search or reading only minimally, or not at all (Mödden et al. 2012). Formally assessed, the overall evidence is unclear and thus restorative visual field training cannot generally be recommended for that purpose.

Further, when compared with hemianopic reading training (see above), the effect of restorative visual field training on reading speed is 7 WPM after therapy, compared to 38.4 WPM improvement after reading training (see above, Kerkhoff 2010). Hence, direct reading training is 5 times more effective and less time-consuming than restorative visual field training when we consider reading speed, which is the main handicap of reading in VFDs.

Moreover, compensatory field training (SCT and reading training) leads to a much quicker reduction of visual impairments and needs fewer treatment sessions. Recently, home-based treatments of visual search and reading have been successfully tested in VFDs (Pambakian et al. 2004; Lane et al. 2010; Aimola et al. 2014). These approaches are cost-effective, but require regular advice by the therapist (i.e. by telephone or visit).

In conclusion, SCT and hemianopic reading training improve visual scanning and "visual" activities of daily living in VFD, and they increase functional independence of the patient reliably (Kerkhoff 1999, 2000; Bouwmeester et al. 2007; Spitzyna et al. 2007; Zihl 2011). Therefore, these two types of treatments are based on a consistent body of study evidence of low-to-moderate quality (observational studies and smaller RCTs with one meta-analysis) showing their effectiveness on visual scanning and transfer of treatment gains to some functional domains of ADL such as reading and mobility as reviewed above. Two recent RCTs underlined these findings: Ivanov et al. (2019) treated children with homonymous VFDs and revealed significant improvements after scanning training in visual search behaviour, reported quality of life and ADLs that remained stable for at least 6 weeks after training at follow-up. Rowe et al. (2016) showed that visual search training was more effective than prism glasses and standard care (no training) in improving vision-related quality of life in patients with VFDs. As a consequence, they should be used for treatment of VFD patients (CEBM classification: level $2 \mathrm{~b}$ to $1 \mathrm{a}$, Grade quality: low to moderate, recommendation: $\mathrm{B}+$ ) (see Fig. 2). 

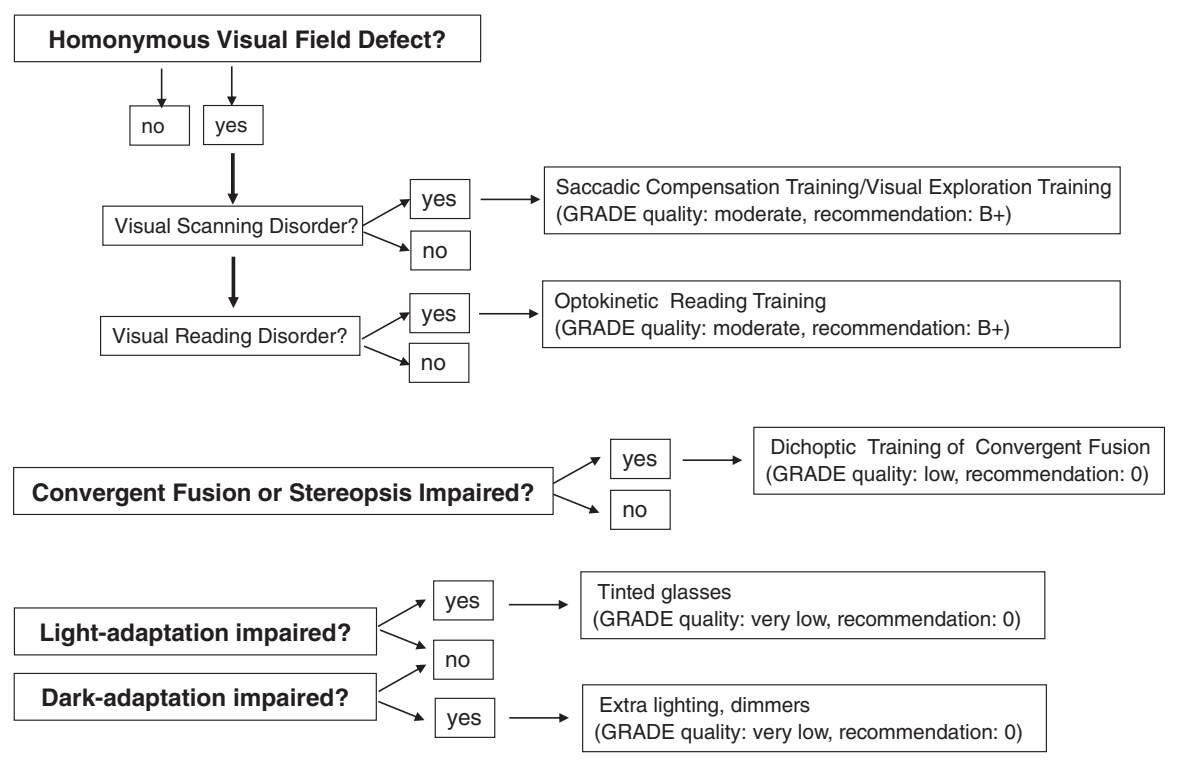

Fig. 2 Clinical pathways for neurovisual rehabilitation

\subsubsection{Ineffective or Disadvantageous Therapies in VFDs}

Most hemianopic patients get confused when using prisms to substitute the visual field loss. However, small prisms fitted to a spectacle can be useful in some cases. Compensatory head shifts towards the scotoma (either spontaneously adopted by the patient or to instruction) are of no use in the rehabilitation of VFDs because they lead to visual exploration deficits in the ipsilesional visual field, strain of the neck muscles, and delay treatment progress in visual scanning training (Kerkhoff et al. 1992a). Training of "blindsight" (the ability of rare cases of cortical blindness who respond to stimuli in their visual field, e.g. by pointing to them, even if they are not able to consciously perceive them) is probably not useful for the majority of the patients because it does not lead to improved functioning in daily life.

\subsubsection{Convergence/Fusion and Stereoscopic Deficits}

Apart from VFDs, other neurovisual deficits occur. Impairments in convergent horizontal fusion represent the most frequent oculomotor deficit after brain damage (Kapoor and Ciuffreda 2002). Importantly, they are often associated with visual perceptual deficits such as loss of stereopsis, reduced reading duration, blurred vision, and asthenopic eye symptoms. This is especially relevant for all visual activities in near-space (reading, writing, smartphone and computer use, typing, knitting, and all visuo-motor activities in near-space). Moreover, it has been shown that righthemispheric vascular lesions cause deficits in stereopsis (Rizzo 1989; Rizzo and Barton 2008). Three recent treatment studies (two controlled group studies, one controlled case series, but none of them randomized controlled) showed that a repetitive binocular fusion treatment using three sorts of dichoptic devices reinstated 
binocular depth perception, stereopsis, and improved reading duration and reduced asthenopic symptoms in chronic brain damage of cerebrovascular, traumatic, or hypoxic aetiology (Schaadt et al. 2013, 2014). As the available observational studies consistently showed a significant treatment effect in about $90 \%$ of treated patients these treatments can be used (CEBM classification: level 2b, Grade quality: low, recommendation: 0) (see Fig. 2).

\subsubsection{Visual Light Adaptation Deficits}

Some $20-30 \%$ of patients with acquired brain damage suffer from feelings of "blinding" and "dark vision" after brain damage (Zihl and Kerkhoff 1990; Jackowski et al. 1996; Kapoor and Ciuffreda 2002; Neumann et al. 2016). The reason for this is an acquired deficit of light and/or dark adaptation of the visual system (not the eye!). Tinted glasses may reduce the feelings of blinding (Jackowski et al. 1996; Kapoor and Ciuffreda 2002), while additional light sources and the use of light dimmers are helpful to cope with dark vision. These treatments do not "heal" the original underlying disorder or light-dark adaptation, but they alleviate the behavioural consequences for the patients and can be used (CEBM classification: level 4, Grade quality: very low, recommendation: 0 ).

Figure 2 summarizes the clinical procedures described herein as a clinical pathway diagram.

\subsubsection{Conclusions}

We have reviewed here the available treatments for the most frequent neurovisual disorders after stroke. However, as pointed out in a recent systematic review on 221 publications about homonymous VFDs, most of the available research has so far focused on body functions, less on activities, and almost never on participation (De Haan et al. 2014). One exception to this may be the treatment of reading because it is an integral part of daily life. So, improvement of reading by reading therapy in hemianopic alexia can be viewed as regaining an important daily activity that enables participation in reading books, newspapers, handwritten notices, short notices on a smartphone, or managing internet banking at home, hence participation.

Moreover, very few studies have analyzed how many patients returned to work after neurovisual rehabilitation. This is an important part of participation and this aspect should be included more often in future treatment studies.

\section{Spatial Neglect, Extinction, and Anosognosia}

Spatial neglect is defined as the inability to respond to sensory stimuli in the contralesional hemispace or body of a neurological patient (Kerkhoff 2001; Husain 2008). In addition to visual, auditory, or tactile neglect, motor neglect often co-occurs as a reduced use of contralesional extremities, i.e. during reaching, standing, or walking. Moreover, neglect patients show a lack of insight into their left-sided sensory and motor deficits termed anosognosia or unawareness. Anosognosia in patients with 
neglect delays recovery (Gialanella et al. 2005) and both are a major source of longterm disability and associated with an adverse rehabilitation outcome (Jehkonen et al. 2006a, b) and longer hospital stays (Kalra et al. 1997). Return to work seems almost impossible in chronic neglect, even after treatment.

Spontaneous recovery from neglect occurs mostly in the first 3 months after stroke (Nijboer et al. 2013). Some 30-40\% of those patients presenting initially with neglect show chronic neglect at 1 year post-lesion (Karnath et al. 2011; Rengachary et al. 2011). The presence of an additional visual field defect reflects larger lesions and predicts chronic neglect as well as severe neglect dyslexia (Ptak et al. 2012). Spatial neglect is most often multimodal (visual, auditory, haptic, olfactory, Kerkhoff 2001). Behavioural recovery is task- and side-specific: while the conspicuous conjugate gaze deviation may be up to $30-40^{\circ}$ ipsilesionally in the first weeks, this recovers continuously within 3 months, paralleled by a more symmetrical, wider visual exploration field of the patient (Aimola et al. 2014). Similarly, visual scanning and cancellation tests improve first on the ipsilesional side, later on the contralesional side (Nijboer et al. 2013). Directional hypokinesia (which designates the phenomenon that neglect patients do not reach far enough to their contralesional side with their intact, nonparetic limb/s) shows better spontaneous recovery than visuospatial inattention (Rengachary et al. 2011).

Moreover, left hemineglect is frequently associated with left hemianopia, which is often difficult to disentangle (pseudo-hemianopia). Left hemianopia worsens the severity of visual neglect. Furthermore, hemiparesis/-plegia and hemi-anaesthesia or hypaesthesia are also often present in patients with left neglect. All these associated deficiencies worsen neglect and reduce the functional effects of rehabilitation.

\subsection{Assessment of Neglect and Associated Disorders}

Assessments should include a visual scanning or exploration task (i.e. crossing out numbers or lines or bells), a standardized text reading task, horizontal and vertical line bisection to detect shifts in the subjective visual midline, and an assessment of anosognosia. The Behavioural Inattention Test (BIT) is a useful test battery to screen for visual neglect in basic and functional tasks (Wilson et al. 1987). Another useful assessment tool for the acute and early post-acute phase is the Catherine Bergego Scale (CBS; Azouvi et al. 2002, 2003, 2006) which assesses visual and body neglect in daily life on a rating scale basis and also anosognosia. Ideally, assessments should also include additional tests of visual, tactile, and auditory extinction-especially in the post-acute phase or when only residual neglect is present. This is important as extinction is often chronic and specific extinction tests are most sensitive to detect such residual neglect symptoms and extinction (for assessment see Lezak et al. 2004).

While most neglect tests assess egocentric neglect phenomena, stimulus-centred or word-centred neglect phenomena may also occur, particularly during reading and visual scanning (Caramazza and Hillis 1990; Hillis et al. 1998) and should be assessed as well. Word-centred neglect phenomena can be detected with a reading 
test (as in hemianopia, see above) or having the patient read compound words. The apples test is useful to disentangle object-centred and egocentred neglect deficits during a visual search task, where different types of apples have to be cancelled out (Bickerton et al. 2011).

\subsection{Rehabilitation of Neglect in the ICF Framework}

\subsubsection{Effects of Neglect Therapy on Disability to Prove}

The latest Cochrane review by Bowen et al. (2013) including 23 randomized clinical trials (628 participants) showed that most studies evaluate the effect of rehabilitation on standardized assessment tests; 15 studies assessed the impact on activities of daily living immediately after rehabilitation and only 6 studies measured these effects at a longer follow-up test after the end of therapy. The currently available results show a significant effect in favour of cognitive rehabilitation, but only on the standardized assessment tests of hemineglect. The effectiveness on the activities of daily life is therefore not rigorously demonstrated.

A limitation in the interpretation of studies is related to the measure of functional impact of cognitive neglect rehabilitation. Indeed, hemineglect is a rarely isolated deficiency, most often associated with multiple sensorimotor and cognitive deficits consecutive to the extent of the brain injury (cf. Kerkhoff 2001). The vast majority of the patients selected in the Cochrane review (last from 2013) had hemineglect due to a stroke of the middle cerebral artery, which was also responsible for leftsided sensory-motor hemiplegia, left-sided hemianopia, and other cognitive deficits such as constructional apraxia, non-lateralized attention deficits, or others. The functional consequences therefore result from all these deficits and not only from hemineglect. Although an improvement of hemineglect is observed after cognitive rehabilitation, it remains in most cases insufficient to decisively reduce the overall measured disability (see Fig. 3).

In addition, the measurement of therapeutic effects on disability is generally carried out by generic assessment scales such as the Barthel Index, the Functional Independence Measure (FIM), or the Activity of Daily Living Scale. A more targeted measurement of the functional consequences of hemineglect can be made by specific scales such as the Catherine Bergego Scale (CBS), provided however that the measured gain is significant in view of the associated deficits and their consequences on the autonomy (Azouvi et al. 2006).

\subsubsection{Cognitive Rehabilitation of Hemineglect Based on the International Classification of Functioning (ICF)}

The International Classification of Functioning (ICF) not only is a reference for holistically understanding the different aspects of a pathology (WHO 2001) but also is a model adapted to the development of neurological rehabilitation strategies (Lexell and Brogårdh 2015). Indeed, the four dimensions described by the classification can be considered as targets for neurorehabilitation (Alford et al. 2015) and cognitive rehabilitation of hemineglect. The first dimension, called "body structure/ 




Fig. 3 Spatial neglect and associated deficiencies in the ICF-Framework

lesion", corresponds to brain anatomical structures that are likely to be activated by re-education via brain plasticity mechanisms. The second dimension, "body function/impairment", refers to the recovery of hemineglect (or clinical subtypes) by selective cognitive rehabilitation techniques (bottom-up and top-down strategies, explicit or implicit learning). The third dimension, "activity/limitation", refers to the reduction of disability and the possible functional generalization of therapeutic effects as well as the improvement of activity through compensation methods. Finally, the fourth dimension, "participation/restriction", refers to the reduction of participation restrictions, notably through improved body function, compensation methods, social interventions, and a better recognition of the deficit and its personal and social consequences (see Table 2).

The ICF model can therefore provide a methodological basis for the development of hemineglect cognitive rehabilitation (Rode et al. 2017). For the specialist in neurorehabilitation and the neuropsychologist, an important question will be to determine what is the best judgment criterion for showing the impact of the interventions. This choice should also take into account the recommendations of Evidence-Based Medicine applied to non-drug therapies (Bowen et al. 2013; Yang et al. 2013).

\section{Therapy of Neglect}

A Cochrane analysis (Bowen et al. 2013) analyzed randomized controlled treatment studies until mid of 2011 and reached the following conclusions: "Eighteen of the 
23 included RCTs compared cognitive rehabilitation with any control intervention (Placebo, attention or no treatment). Meta-analyses demonstrated no statistically significant effect of cognitive rehabilitation, compared with control, for persisting effects on either ADL (5 studies, 143 participants) or standardised neglect $\mathrm{f}$ ( 8 studies, 172 participants), or for immediate effects on ADL (10 studies, 343 participants). In contrast, we found a statistically significant effect in favour of cognitive rehabilitation compared with control, for immediate effects on standardised neglect assessments (16 studies, 437 participants), standardised mean difference (SMD) $0.35,95 \%$ confidence interval (CI) $0.09-0.62$. However sensitivity analyses including only studies with high methodological quality removed evidence of a significant effect of cognitive rehabilitation". As a consequence, the authors gave no clear recommendations for therapy. In the meanwhile, several well-controlled randomized treatment studies have been published that allow some recommendations. Several reviews have described the available treatments in detail (Kerkhoff and Schenk 2012; Bowen et al. 2013). Therefore, only a condensed survey of these treatments is given here (see the text below and Table 3), focussing on the currently documented therapeutic effects on visual neglect (which is the most often targeted domain in treatment studies), and also on nonvisual (tactile, auditory) neglect, sensory extinction, anosognosia, activities of daily living (ADLs), and motor/postural functions, if such effects have been published (for review see Kerkhoff and Schenk 2012). The references, therapeutic approaches, documented effects, the level of evidence

Table 2 The International Classification of Functioning (ICF), a model adapted to strategies of cognitive rehabilitation of hemineglect

\begin{tabular}{|c|c|c|}
\hline Normal & Pathology & Intervention \\
\hline $\begin{array}{l}\text { Body } \\
\text { structure }\end{array}$ & Lesion & $\begin{array}{l}\text { Plasticity (structural, functional)—vicariousness } \\
\text { Stimulation of undamaged nervous system structures by } \\
\text { neuromodulation (rTMS, tDCS) }\end{array}$ \\
\hline $\begin{array}{l}\text { Body } \\
\text { function }\end{array}$ & Impairment & $\begin{array}{l}\text { Recovery, restoration } \\
\text { Top-down approaches } \\
\text { Visual scanning training (VST) } \\
\text { Attentional Cueing } \\
\text { Mental practice or imagery } \\
\text { Bottom-up approaches } \\
\text { Sensory stimulation (optokinetic, vestibular, } \\
\text { proprioceptive, neck vibration) } \\
\text { Prism adaptation } \\
\text { Half-field eye patching } \\
\text { Spatio-motor cueing } \\
\text { Arm-activation intervention } \\
\text { Mirror therapy }\end{array}$ \\
\hline Activity & $\begin{array}{l}\text { Activity } \\
\text { limitation }\end{array}$ & $\begin{array}{l}\text { Functional generalization } \\
\text { Compensation by equipment (technical help, connects object) } \\
\text { Compensation by caregivers or environment }\end{array}$ \\
\hline Participation & $\begin{array}{l}\text { Participation } \\
\text { restriction }\end{array}$ & $\begin{array}{l}\text { Compensation by family, people, society (legal, economic, } \\
\text { politic dimensions); Recognition, inclusion }\end{array}$ \\
\hline
\end{tabular}




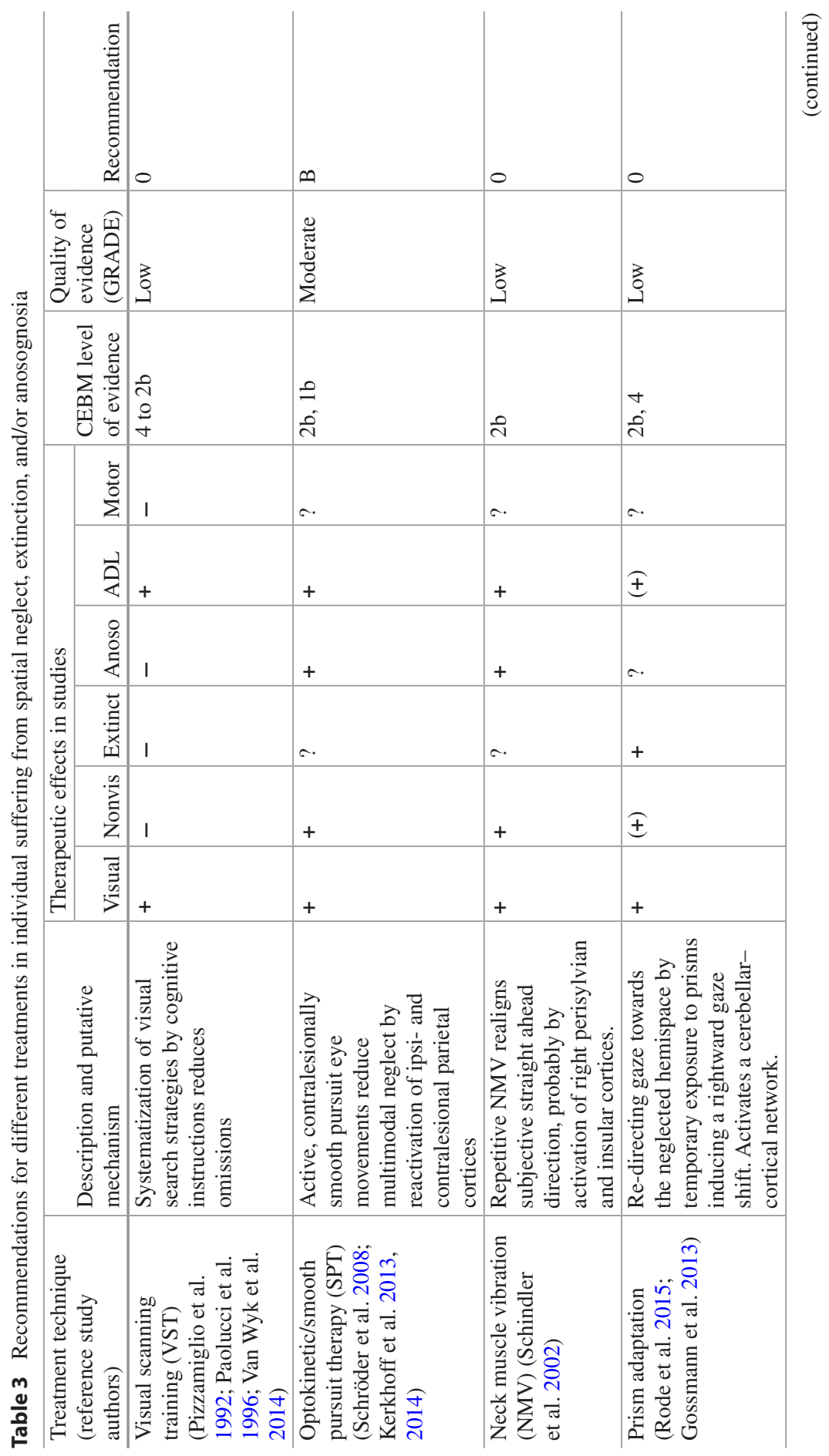




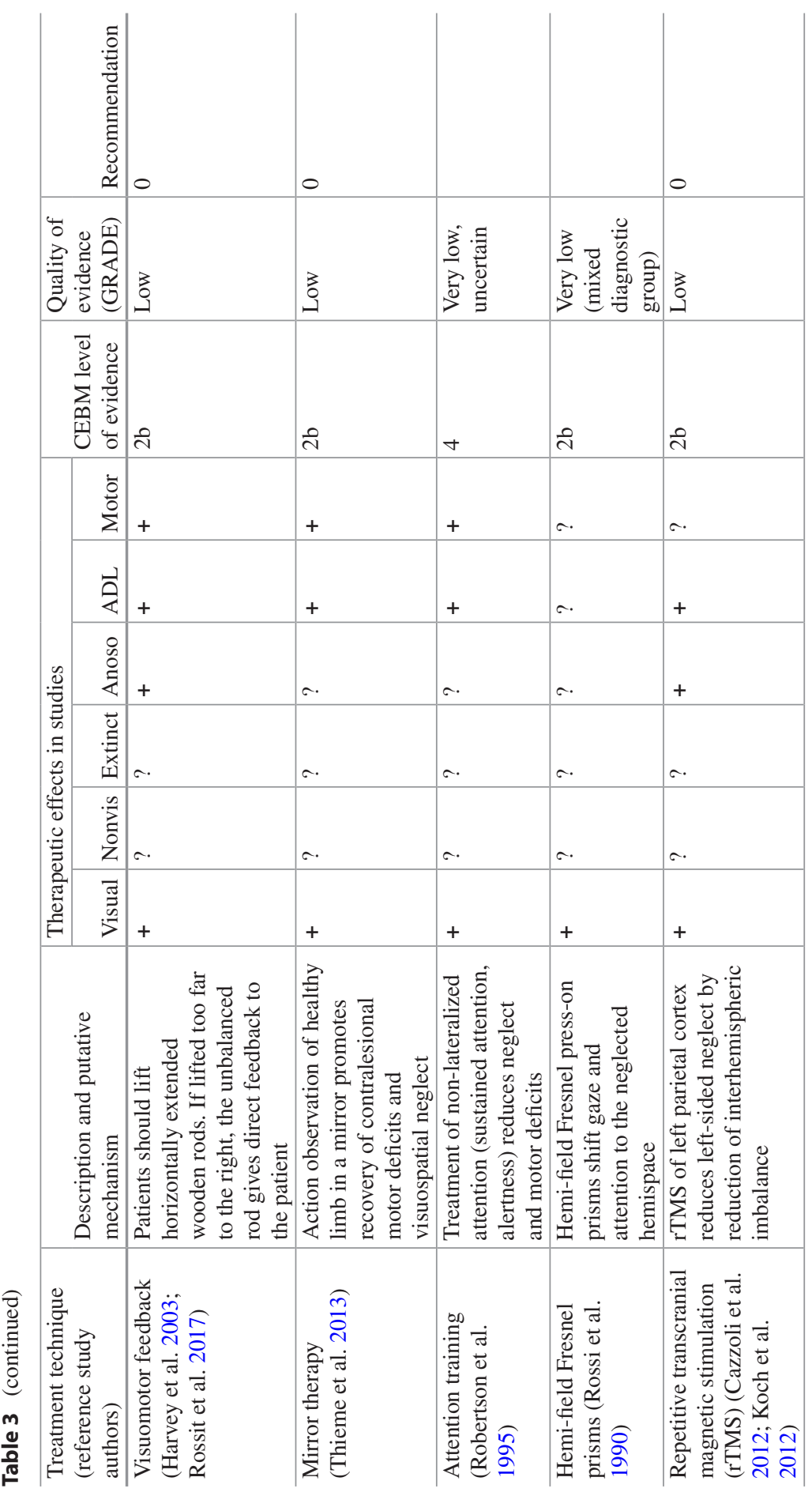




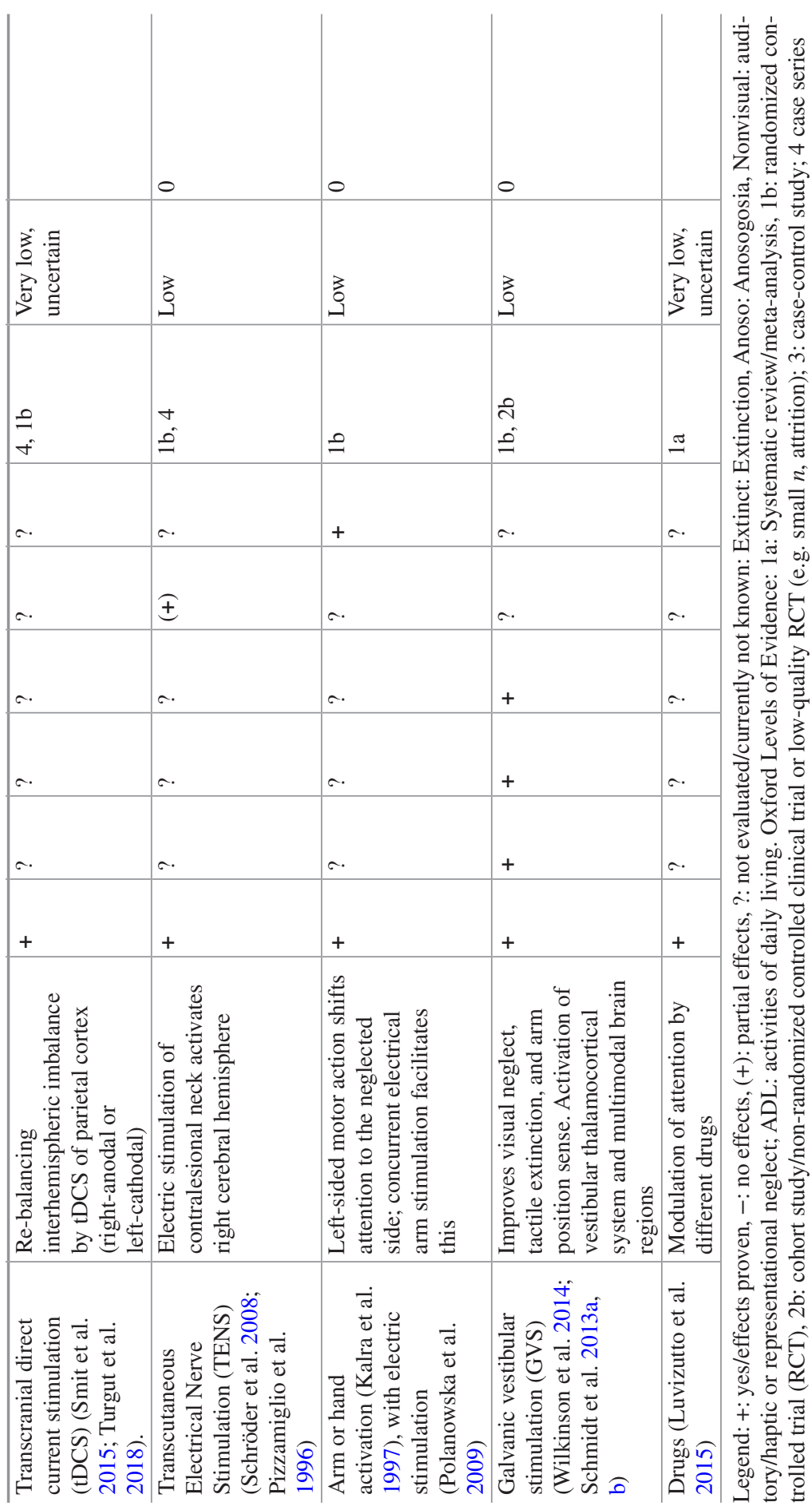


(CEBM), the quality of evidence, and strength of recommendation (GRADE) are presented in Table 3 (see also Platz 2017).

\subsection{Description of Treatments for Neglect}

While with exception of the Optokinetic/smooth pursuit therapy (SPT), the quality of evidence available is too low to give a weak or strong recommendation, there is nevertheless a variety of therapeutic options that are supported by clinical experience. The résumés presented below are therefore expert opinion.

In visual scanning training (VST or exploration training), patients typically look at a visual display (on a table, a computer screen, or a large projection wall) on which different classes of visual stimuli (i.e. stars, circles, numbers, photos from real objects) are shown, and the patient is required to look for a specific class of stimuli ("Search for all stars and point to them", with a stick or laser pointer or on a touch screen). Patients are verbally instructed to look to the neglected side ("cueing of attention"), search systematically row by row as in reading in order to acquire a systematic search strategy. By this, the number of omissions and search time is reduced.

Résumé: VST is the most widely used treatment for neglect and improves selectively visual neglect in scanning and related tasks, but has no effect on non-visual neglect. It can easily be realized but requires many sessions to be effective $(>40)$. It is difficult to implement in the early phase (first 2 months after stroke) because it requires some awareness and cooperation on the patient's side.

Optokinetic/smooth pursuit therapy $(O K S, S P T)$ : Patients are instructed to make following (pursuit) eye movements to visual stimuli that move slowly towards the neglected field. The stimuli are usually presented on a computer screen or via beamer to a large projection wall via specific software. When the patient has reached with his eyes the neglected side of space, he is instructed to remain there with his eyes for some seconds, before the task is repeated. OKS/SPT can be performed early after stroke at the bedside, or later. Twenty or more sessions (á 30-min) are recommended.

Résumé: OKS/SPT is more effective than scanning therapy and can be implemented earlier. Improvements transfer to a wide variety of visual and non-visual neglect domains and reduce anosognosia.

Neck-muscle vibration (NMV): During NMV therapy, the patient's contralesional neck muscles (hence left neck in left neglect) are vibrated with a conventional vibrator (either battery-driven or not; with a small vibration head, $<2 \mathrm{~cm}$ diameter, and a vibration frequency $>60-80 \mathrm{~Hz}$ ). This induces activation of muscle spindles and leads to a relocation of gaze (eye and head position) towards a more symmetrical, midline position. The vibrator is usually held by the therapist, which can be demanding for the therapist as he/she will feel the vibration as well and has to do it for at least 20 sessions (á $30 \mathrm{~min}$ ).

Résumé: NMV is easy to apply but is more demanding for the therapist holding the vibrator. On the other hand, a battery-driven vibrator makes therapy more 
flexible and mobile, thus therapy can be performed at the bedside, in physio or occupational therapy, or at home.

Prism adaptation (PA): This therapy requires a conventional spectacle on which two prism glasses are mounted inducing a gaze shift to the ipsilesional side (hence to the right in left neglect). This prism goggle is worn by the patient only for the period of the prism exposure (not during the day, especially not during walking!). The prism exposure lasts typically for 20-30 min per session, and this should be repeated (several times per week). While the patient wears the prism goggles, he/she carries out visuo-motor tasks. These can be pointing to marked locations on a table, or reaching for objects in daily life (i.e. cups or glasses on a table or in a bookshelf). After this exposure period, the goggles are taken off and the therapeutic after-effect occurs (re-orienting of spatial attention to the neglected side). This can be used for other subsequent therapies (i.e. motor, postural, reading, cognitive ...). Twenty or more sessions (á 20-30 min) are recommended.

Résumé: PA is a widely used tool for neglect therapy that works best with a $10^{\circ}$ prism (not smaller prism angle!) and is also mobile and relatively easy to apply.

Visuo-motorfeedback $(V F)$ : The patient has to lift wooden or metal rods with his ipsilesional hand (index finger and thumb), so that their left and right half are balanced and the rod does not fall to one side. As the patient ignores initially the contralesional side of the rod (due to his neglect), he will grasp it more to the right side and consequently the bar will fall to the left side. This "natural" feedback leads to a subsequent adaptation of the patient's lifting behaviour, thus lifting the rods more accurately in the middle part during the course of the therapy. Twenty or more sessions (á 20-30 min) recommended.

Résumé: VF is an easily applicable and low-cost treatment that can be implemented in different settings, including the patient's home. This makes it flexible and mobile.

Mirror therapy (MT): MT is a well-established treatment for therapy of motor impairments (of the hemiparetic arm or leg). It requires a vertically oriented mirror which is placed in front of the patient's breast so that he can view his ipsilesional hand/arm/leg performing different motor tasks. This action observation facilitates motor recovery of the impaired extremity behind the mirror. MT has shown therapeutic effects in patients with left-sided hemiparesis and left-sided visual neglect. Twenty or more sessions (á 20-30 min) recommended.

Résumé: MT is an easily applicable, low-cost therapy which can be used as an add-on treatment (not as a primary neglect therapy) for neglect.

Attention training: Alertness and sustained attention can be trained by various ways: by computer-based training and specific software, by table-top exercises, and also by motor (for instance treadmill) training. Improvements in attention lead to better performance in neglect-specific tasks, especially dual-tasks (i.e. looking and recollecting numbers heard, or looking and walking simultaneously).

Résumé: Attention training can be an element of neglect therapy. However, therapy should not rely solely on computerized training as such improvements are often not stable in the long term. 
Hemifield Fresnel Prisms: Press-on (Fresnel) prism foils are attached on the contralesional side of the two glasses of a conventional spectacle sparing the central (macular) visual field region. This induces a gaze shift towards the neglected side (hence opposite to that in prism adaptation, see above).

Résumé: Easy-to-use technique, which should be used only during sitting and when the patient is not involved in transfers or other potentially dangerous activities, as the prism distorts the visual field. The central $10^{\circ}$ of each glass should be free from foil to enable unimpaired central vision. Fresnel prisms reduce visual acuity by some $10-20 \%$.

Repetitive transcranial magnetic stimulation (rTMS): During rTMS, a magnetic coil attached to a magnetic stimulator is hold by a medical doctor over the nonlesioned parietal cortex (hence the intact) hemisphere, to re-balance the attentional systems of both hemispheres. Left parietal attentional systems are typically hyperactive in patients with left neglect thus preventing the lesioned right-sided attentional systems from functional recovery. rTMS temporarily dampens the leftward hyperactive systems, thus improving functional recovery. This works without the patient being attentive, but care must be taken not to induce fits. Twenty or more sessions (á $20 \mathrm{~min}$ ) are recommended.

Résumé: rTMS (or theta burst stimulation) is the most costliest neglect therapy to date and requires medical staff. It can be used earlier than other treatments as the mechanism of action does not require awareness or active cooperation from the patient. An optional add-on treatment when safety criteria are followed.

Transcranial direct current stimulation (tDCS): Similar principle of action as in rTMS, but instead of magnetic pulses, weak electrical currents are delivered via two electrodes over the two parietal lobes. Twenty or more sessions (of $20 \mathrm{~min}$ ) are recommended.

Résumé: Less costly than rTMS, but often the technique cannot be applied due to exclusion criteria for safety reasons (fits, open scull) or is difficult to apply because of hairy skin thus preventing the flow of electric currents.

Transcutaneous electrical nerve stimulation (TENS): Application of weak electrical currents to the contralesional neck/upper back. Portable, low-cost technique, easily applicable, and no safety problems. Twenty or more sessions (á $20 \mathrm{~min}$ ) recommended.

Résumé: Suitable as an add-on treatment, probably less suited as a primary and sole neglect therapy. It has good effects also on postural imbalance and nonlateralized attention.

Arm/hand activation with/without peripheral electrical stimulation: The method entails volitional movement of the contralesional limbs (i.e. opening and closing the hand). This can be facilitated by the additional application of electrodes to the neglected limb.

Résumé: Limb activation is often not applicable in the early phase of neglect because of severe hemiparesis or plegia. Later, with concurrent electrical stimulation, it is a useful, low-cost technique that particularly addresses neglect of the 
neglected extremities which is not targeted by the majority of other neglect treatments (except GVS, see below).

Galvanic vestibular stimulation (GVS): Application of weak electrical current via two electrodes attached behind both ears (over the mastoid bones) activates the vestibular system via the vestibular nerves. This has good therapeutic effects on body-related neglect (tactile extinction, sense of arm position for the neglected limb and visual neglect). Same limitations for safety reasons as in rTMS and tDCS (no fits). Twenty or more sessions (of $20 \mathrm{~min}$ ) recommended.

Résumé: A suitable add-on treatment, especially for the body-related phenomena of neglect. The same electrical stimulators as used for tDCS can be used.

Drugs: The administration of attention-enhancing drugs is intended to improve non-lateralized attention (alertness), thereby reducing neglect. Moreover, antidepressant drugs can improve attention.

Résumé: Potentially, drugs may be helpful as an add-on treatment (not as a primary neglect therapy). Unfortunately, the therapeutic effects are inconsistent and many potential interactions with other drugs the patient must take have to be considered. Antidepressants given because of post-stroke depression may have an additional positive effect on neglect but should not be the primary reason for their prescription.

\subsection{Clinical Decision-Making: Which Therapy, When, Which Dose, and Which Combinations?}

While some treatments may be classified as "bottom-up" treatments because they manipulate a specific sensory input channel (i.e. vestibular), others ("top-down") intend to change cognitive strategies (i.e. sustained attention, visual scanning) in order to compensate for neglect. While the knowledge about the exact action profile of these different treatments is still incomplete, some treatment-relevant conclusions can be drawn. First, only a few treatments induce multimodal effects in the visual and nonvisual modalities, while others improve neglect only in one modality (mostly the visual). Second, not all treatments show transfer effects to ADL and to motor/postural capacities, both of which are very important for gaining functional independence for the patient. Finally, no treatment is currently available that affects all components and modalities of neglect and associated disorders. It is-in our personal opinion - therefore more likely to achieve a better treatment outcome by using several different treatments in combination-either simultaneously or sequentially-than expecting that neglect can be cured by using one specific treatment alone.

According to a recent Cochrane analysis, evaluating the effects of drugs therapy on neglect (Luvizutto et al. 2015), the quality of the evidence from available RCTs was very low. The effectiveness and safety of pharmacological interventions for neglect after stroke are therefore uncertain. Hence, drug therapy cannot be recommended for the treatment of spatial neglect or associated disorders. 
For the clinician, the question arises: which of these different treatments should be used, when, how long, and how often? Although many of these questions are currently unanswered by scientific research, some practical recommendations based on the literature and own clinical experience may be given:

- Early phase after stroke (first 2 months): Use methods that need less cognitive control, awareness, and cooperation from the patient: rTMS, TENS, OKS/SPT, neck muscle vibration. If feasible, start therapy already at the bedside.

- Post-acute phase after stroke (after month 2 post-onset): Add methods that require more active cooperation and participation from the patient during therapy: visual scanning therapy, attention training, mirror therapy, visuo-motor feedback, and arm activation with concurrent electrical stimulation.

- Late phase after stroke (>6 months post-onset): Introduce more dual- tasks into therapy because in daily life the patient is often faced with such demands (i.e. looking and talking or walking and looking). This can be done by adding a cognitive task to the primary therapeutic task (i.e. count backwards while scanning for objects on a table-top) or scanning visual scenes on a computer screen. Try therapy with the patient standing instead of sitting. Mobility is of utmost importance for most neglect patients (see the chapter by Pèrennou et al., this volume) and the neglect impairs mobility and postural safety. Thus, neglect therapy can be performed during stance looking at stimuli projected (via beamer) on a white wall or while the patient is standing or walking on a treadmill.

- Seeing straight: In the first months after stroke, it is important that the patient sees "more straight" instead of ignoring one side and looking always to the ipsilesional side.

- Systematic scanning strategy: Later, when the patient can look better to the neglected side, it is important that he can select certain stimuli while ignoring other things. This can be achieved by a systematic scanning strategy taught to the patient (i.e.): "Start looking always on the top left side row by row, scan horizontally row by row. Don't forget the left lower corner, as it is the most often neglected part of the scene (also in daily life)".

- Multidisciplinary treatments: Try to implement treatments that span different vocational specialties in your rehab-team: for instance, try to combine physiotherapy with i.e. neck muscle vibration or TENS or attention training in addition with motor therapy for hand function.

- Motor and Postural Functions: Left-sided motor functions are often more impaired in patients with neglect than those without neglect (both with hemiparesis or plegia). Specific neglect therapy augments the effects of physiotherapy. Try to combine postural training (i.e. standing during neglect therapy, or with an additional balance pad or on a treadmill with stabilization) with neglect therapy (i.e. visual scanning training, OKS/SPT, attention training).

- Visuospatial disorders: Neglect is not a unitary disorder, but rather a multicomponent complex disease with—due to larger lesions—-more associated deficits. Often, visuospatial perception (line orientation, subjective visual, or haptic vertical) and visuo-construction are impaired due to parietal lesions. The prior can be 
treated for instance with GVS, the latter with specific visuo-constructive therapy. This improves visuo-motor performance in daily life.

- Exploit after-effects: Use the known after-effects of several of these treatments (i.e. prism adaptation, OKS/SPT, NMV, rTMS, TENS) for the next therapy afterwards; they facilitate the subsequent therapy.

- Start early: Use the morning instead of the afternoon for therapy, patients are more alert. In the early rehab phase, 20-30 min continuous neglect therapy is often the limit and preferable to 1-h sessions.

- Dose: More therapy induces more improvements although this remains to be proven scientifically. This can be reached by implementing different neglect therapies into the treatments delivered by different therapists (i.e. nurse, physiotherapist, occupational therapist, neuropsychologist, social worker, recreation therapist, relative at home).

- Awareness/Anosognosia: Improved awareness comes gradually (a) by certain treatments (i.e. OKS/SPT or neck muscle vibration, or awareness training) and (b) by improving the patient's and relatives' knowledge about the impairments and treatment progress. This is a joint task of the whole rehab team.

- As a note of caution, it needs to be added that technical devices may not be licensed for the specific use mentioned; if that was the case, any application would be "off label" and related medico-legal aspects need to be considered.

- Late course of the disease: Moreover, most "therapy knowledge" comes from the first year after stroke. Almost nothing is known about the very late outcome from neglect several years after a stroke. There could be later functional recovery, a change of neglect type and/or some adaptation to the deficit. Such aspects should be evaluated in future treatment research.

\subsection{Therapy of Sensory Extinction}

Sensory extinction may be associated with spatial neglect or dissociate from it (Kerkhoff 2001). In the acute stage, both are often difficult to disentangle. In the chronic stage, extinction is often present although overt neglect signs have vanished. Extinction may persist for years after a stroke and impairs functional independence (i.e. tactile extinction impairs ADLs, visual extinction impairs driving!). Only one treatment has so far shown lasting and significant treatment effects on extinction; Galvanic vestibular stimulation reduced tactile extinction permanently (Schmidt et al. 2013b).

\subsection{Therapy of Anosognosia in Neglect}

Improving awareness (or reducing anosognosia) is crucial when aiming at a better outcome for patients with neglect and anosognosia. Few studies have shown treatment effects on unawareness after specific therapy. After repetitive neck muscle vibration, ADL functions and unawareness (as assessed from a rating scale) 
improved significantly (Schindler et al. 2002). Moreover, repetitive optokinetic therapy (SPT) reduced unawareness significantly (again rated from staff), while visual scanning therapy had no effect on unawareness (Kerkhoff et al. 2014). Jenkinson et al. (2011) summarized helpful treatment strategies in anosognosia for hemiplegia, which is often but not always present in the early phase of neglect. These strategies require systematic evaluation in further controlled treatment studies.

\subsection{Conclusions}

The last two decades have seen a dramatic increase in the number of techniques available for the treatment of unilateral neglect and associated disorders (reviewed in Kerkhoff and Schenk 2012). Many of these techniques were developed from experimental interventions designed to influence the rightward orientation bias of neglect patients. These sensory stimulation techniques have some obvious advantages. They are easy to apply, their effects tend to generalize, and they only require minimal patient compliance-a huge benefit in the case of a disorder that is frequently associated with anosognosia. The induced improvements can last for several weeks when multiple treatment sessions are applied. However, the initial hope for a quick cure for neglect after only one or few treatment sessions has turned out to be unrealistic. Instead, a higher number of treatment sessions are probably necessary to reach functional improvements that last for a sufficiently long time and not only for 1 or 2 weeks. The challenge today is to select the best tool for a given patient and to combine this with other effective treatments to maximize outcome. We have formulated several practical recommendations which can be implemented into neurorehab teams in order to facilitate the transfer of novel knowledge, techniques, and treatments into clinical practice. Finally, we should keep in mind that neglect is not a unitary disorder but rather a complex, multicomponential disease. This requires-like other complex diseases-multiple, coordinated single treatments as we have tried to outline in this chapter.

\section{References}

Aimola L, Lane AL, Smith DT, Kerkhoff G, Ford G, Schenk T (2014) Efficacy and feasibility of a home-based computer training for individuals with homonymous visual field defects. Neurorehabil Neural Repair 28:207-218

Alford VM, Ewen S, Webb GR, McGinley J, Brookes A, Remedios LJ (2015) The use of the International Classification of Functioning, Disability and Health to understand the health and functioning experiences of people with chronic conditions from the person perspective: a systematic review. Disabil Rehabil 37:655-666

Azouvi P, Samuel C, Louis-Dreyfus A, Bernati T, Bartolomeo P, Beis J-M, Chokron S, Leclercq M, Marchal F, Martin Y, De Montety G, Olivier S, Perennou D, Pradat-Diehl P, Prairial C, Rode G, Siéroff E, Wiart L, Rousseaux M, French Collaborative Study Group on Assessment of Unilateral Neglect (GEREN/GRECO) (2002) Sensitivity of clinical and behavioural tests of spatial neglect after right hemisphere stroke. J Neurol Neurosurg Psychiatry 73:160-166 
Azouvi P, Olivier S, De Montety G, Samuel C, Louis-Dreyfus A, Tesio L (2003) Behavioural assessment of unilateral neglect: study of the psychometric properties of the Catherine Bergego Scale. Arch Phys Med Rehabil 84:51-57

Azouvi P, Bartolomeo P, Beis JM, Perennou D, Pradat-Diehl P, Rousseaux M (2006) A battery of tests for the quantitative assessment of unilateral neglect. Restor Neurol Neurosci 24:273-285

Barton JJS, Black S (1998) Line bisection in hemianopia. J Neurol Neurochir Psychiatr 64(5):660-662

Bickerton W-L, Samson D, Williamson J, Humphreys GW (2011) Separating forms of neglect using the Apples Test: validation and functional prediction in chronic and acute stroke. Neuropsychology 25:567-580

Biousse V, Newman NJ (2009) Neuro-opthalmology illustrated. Thieme, New York

Bouwmeester L, Heutink J, Lucas C (2007) The effect of visual training for patients with visual field defects due to brain damage: a systematic review. J Neurol Neurosurg Psychiatry 78(6):555-564

Bowen A, Hazelton C, Pollock A, Lincoln NB (2013) Cognitive rehabilitation for spatial neglect following stroke. Cochrane Database Syst Rev 2013(7):CD003586

Caramazza A, Hillis AE (1990) Levels of representation, co-ordinate frames, and unilateral neglect. Cogn Neuropsychol 7(5-6):391-445

Cazzoli D, Muri RM, Schumacher R et al (2012) Theta burst stimulation reduces disability during the activities of daily living in spatial neglect. Brain 135:3426-3429

De Haan G, Heutink J, Melis-Dankers BJM, Tucha O, Brouwer W (2014) Spontaneous recovery and treatment effecs in patients with homonymous visual field defects: a meta-analysis of existing literature in terms of the ICF framework. Surv Ophthalmol 59:77-96

De Haan G, Melis-Dankers BJ, Brouwer WH, Bredewoud RA, Tucha O, Heutink J (2015) The effects of compensatory scanning training on mobility in patients with homonymous visual field defects: a randomized controlled trial. PLoS One 10(8):e134459

Gialanella B, Monguzzi V, Santoro R, Rocchi S (2005) Functional recovery after hemiplegia in patients with neglect: the rehabilitative role of anosognosia. Stroke 36:2687-2690

Gossmann A, Kastrup A, Kerkhoff G, Herrero CL, Hildebrandt H (2013) Prism adaptation improves ego-centered but not allocentric neglect in early rehabilitation patients. Neurorehabil Neural Repair 27:534-541

Guyatt GH, Oxman AD, Vist GE, Kunz R, Falck-Ytter Y, Alonso-Coello P, Schünemann JJ (2008) GRADE: an emerging consensus on rating quality of evidence and strength of recommendation. BMJ 336:924-926

Harvey M, Hood B, North A, Robertson IH (2003) The effects of visuomotor feedback training on the recovery of hemispatial neglect symptoms: assessment of a 2-week and follow-up intervention. Neuropsychologia 41:886-893

Hesse C, Lane AR, Aimola L, Schenk T (2012) Pathways involved in human conscious vision contribute to obstacle-avoidance behaviour. Eur J Neurosci 36:2383-2390

Hillis AE, Rapp B, Benzing L, Caramazza A (1998) Dissociable coordinate frames of unilateral spatial neglect: "viewer-centered" neglect. Brain Cogn 37(3):491-526

Husain M (2008) Hemispatial neglect. In: Goldenberg G, Miller BV (eds) Handbook of clinical neurology. Elsevier B.V., Amsterdam, pp 359-372

Ivanov IV, Kuester S, MacKeben M, Krumm A, Haaga M, Staudt M, Cordey A, Gehrlich C, Martus P, Trauzettel-Klosinski S (2019) Effects of visual search training in children with hemianopia. PLoS One 13(7):e0197285

Jackowski MM, Sturr JF, Taub HA, Turk MA (1996) Photophobia in patients with traumatic brain injury-uses of light-filtering lenses to enhance contrast sensitivity and reading rate. NeuroRehabilitation 6:193-201

Jehkonen M, Laihosalo M, Kettunen J (2006a) Anosognosia after stroke: assessment, occurrence, subtypes and impact on functional outcome reviewed. Acta Neurol Scand 114:293-306

Jehkonen M, Laihosalo M, Kettunen JE (2006b) Impact of neglect on functional outcome after stroke: a review of methodological issues and recent research findings. Restor Neurol Neurosci 24:209-215 
Jenkinson PM, Preston C, Ellis SJ (2011) Unawareness after stroke: a review and practical guide to understanding, assessing, and managing anosognosia for hemiplegia. J Clin Exp Neuropsychol 33:1079-1093

Kalra L, Perez I, Gupta S, Wittink M (1997) The influence of visual neglect on stroke rehabilitation. Stroke 28:1386-1391

Kapoor N, Ciuffreda KJ (2002) Vision disturbances following traumatic brain injury. Curr Treat Options Neurol 4:271-280

Karnath HO, Rennig J, Johannsen L, Rorden C (2011) The anatomy underlying acute versus chronic spatial neglect: a longitudinal study. Brain 134:903-912

Kasten E, Wüst S, Behrens-Baumann W, Sabel BA (1998) Computer-based training for the treatment of partial blindness. Nat Med 4:1083-1087

Keller I, Lefin-Rank (2010) Improvement of visual search after audiovisual exploration training in hemianopic patients. Neurorehabil and Neural Repair 24:666-673

Kerkhoff G (1993) Displacement of the egocentric visual midline in altitudinal postchiasmatic scotomata. Neuropsychologia 31:261-265

Kerkhoff G, Münßinger U, Meier EK (1994) Neurovisual rehabilitation in cerebral blindness. Arch Neurol 51:474-481

Kerkhoff G (1999) Restorative and compensatory therapy approaches in cerebral blindness-a review. Restor Neurol Neurosci 15(2-3):255-271

Kerkhoff G (2000) Neurovisual rehabilitation: recent developments and future directions. J Neurol Neurosurg Psychiatry 68:691-706

Kerkhoff G (2001) Hemispatial neglect in man. Prog Neurobiol 63:1-27

Kerkhoff G (2010) Evidenczbasierte Verfahren in der neurovisuellen Rehabiliation. Neurol Rehabil 16:82-90

Kerkhoff G, Schenk T (2011) Line bisection in homonymous visual field defects—recent findings and future directions. Cortex 47(1):53-58

Kerkhoff G, Schenk T (2012) Rehabilitation of neglect: an update. Neuropsychologia 6:1072-1079

Kerkhoff G, Munssinger U, Haaf E, Eberle-Strauss G, Stogerer E (1992a) Rehabilitation of homonymous scotomata in patients with postgeniculate damage of the visual system: saccadic compensation training. Restor Neurol Neurosci 4(4):245-254

Kerkhoff G, Münßinger U, Eberle-Strauss G, Stögerer E (1992b) Rehabilitation of hemianopic alexia in patients with postgeniculate visual field disorders. Neuropsychol Rehabil 2(1):21-42

Kerkhoff G, Reinhart S, Ziegler W, Artinger F, Marquardt C, Keller I (2013) Smooth pursuit eye movement training promotes recovery from auditory and visual neglect: a randomized controlled study. Neurorehabil Neural Repair 27:789-798

Kerkhoff G, Bucher L, Brasse M et al (2014) Smooth pursuit "bedside" training reduces disability and unawareness during the activities of daily living in neglect. A randomized controlled trial. Neurorehabil Neural Repair 28:554-563

Kerr NM, Chew SS, Eady EK, Gamble GD, Danesh-Meyer HV (2010) Diagnostic accuracy of confrontation visual field tests. Neurology 74(15):1184-1190

Koch G, Bonnì S, Giacobbe V, Bucchi G, Basile B, Lupo F, Versace V, Bozzali M, Caltagirone C (2012) Theta-burst stimulation of the left hemisphere accelerates recovery of hemispatial neglect. Neurology 78:24-30

Lane A, Smith DT, Elison A, Schenk T (2010) Visual exploration training is no better than attention training for treating hemianopia. Brain 133(6):1717-1728

Lexell J, Brogårdh C (2015) The use of ICF in the neurorehabilitation process. NeuroRehabilitation 36:5-9

Lezak MD, Howieson E, Bigler E, Tranel D (2004) Neuropsychological assessment. Oxford University Press, New York

Luvizutto GJ, Bazan R, Braga GP, Resende LA, Bazan SG, El Dib R (2015) Pharmacological interventions for unilateral spatial neglect after stroke. Cochrane Database Syst Rev 2015(11):CD010882

Machner B, Sprenger A, Sander T, Heide W, Kimmig H, Helmchen C et al (2009) Visual search disorders in acute and chronic homonymous hemianopia: lesion effects and adaptive strategies. Ann N Y Acad Sci 1164:419-426 
Mödden C, Behrens M, Damke I, Eilers N, Kastrup A, Hildebrandt H (2012) A randomized controlled trial comparing 2 interventions for visual field loss with standard occupational therapy during inpatient stroke rehabilitation. Neurorehabil Neural Repair 26(5):463-469

Nelles G, Esser J, Eckstein A, Tiede A, Gerhard H, Diener HC (2001) Compensatory visual field training for patients with hemianopia after stroke. Neurosci Lett 306:189-192

Neumann G, Schaadt AK, Reinhart S, Kerkhoff G (2016) Clinical and psychometric evaluations of the cerebral vision screening questionnaire in 461 nonaphasic individuals poststroke. Neurorehabil Neural Repair 30:187-198

Nijboer TC, Kollen BJ, Kwakkel G (2013) Time course of visuospatial neglect early after stroke: a longitudinal cohort study. Cortex 49:2021-2027

Pambakian AL, Mannan SK, Hodgson TL, Kennard C (2004) Saccadic visual search training: a treatment for patients with homonymous hemianopia. J Neurol Neurosurg Psychiatry 75(10): 1443-1448

Paolucci S, Antonucci G, Guariglia C, Magnotti L, Pizzamiglio L, Zoccolotti P (1996) Facilitatory effect of neglect rehabilitation on the recovery of left hemiplegic stroke patients-a cross-over study. J Neurol 243:308-314

Pizzamiglio L, Antonucci G, Judica A, Montenero P, Razzano C, Zoccolotti P (1992) Cognitive rehabilitation of the hemineglect disorder in chronic patients with unilateral right brain damage. J Clin Exp Neuropsychol 14:901-923

Pizzamiglio L, Vallar G, Magnotti L (1996) Transcutaeneous electrical stimulation of the neck muscles and hemineglect rehabilitation. Rest Neur Neurosi 10:197-203

Platz T (2017) Practice guidelines in neurorehabilitation. Neurology International Open 1:E148-E152

Polanowska K, Seniow J, Paprot E, Lesniak M, Czlonkowska A (2009) Left-hand somatosensory stimulation combined with visual scanning training in rehabilitation for post-stroke hemineglect: a randomised, double-blind study. Neuropsychol Rehabil 19:364-382

Pollock A, Zazelton C, Henderson CA, Angilley J, Dhillon B, Lanthorne P, Livingstone K, Munro FA, Heather O, Row F, Shahani U (2012) Interventions for visual field defects in patients with stroke. Stroke 43:e37-e38

Ptak R, Di PM, Schnider A (2012) The neural correlates of object-centered processing in reading: a lesion study of neglect dyslexia. Neuropsychologia 50:1142-1150

Rengachary J, He BJ, Shulman GL, Corbetta M (2011) A behavioral analysis of spatial neglect and its recovery after stroke. Front Hum Neurosci 5:29

Rizzo M (1989) Astereopsis. In: Boller F, Grafman J (eds) Handbook of neuropsychology. Elsevier, Amsterdam, pp 415-427

Rizzo M, Barton JJS (2008) Central disorders of visual function. In: Miller NR, Newman NJ, Biousse V, Kerrison JB (eds) Walsh and Hoyt'a clinical neuro-opthalmology: the essentials. Lippincott Williams \& Wilkins, Philadelphia, pp 263-284

Robertson IH, Tegnér R, Tham K, Lo A, Nimmo-Smith I (1995) Sustained attention training for unilateral neglect: theoretical and rehabilitation implications. J Clin Exp Neuropsychol $17: 416-430$

Rode G, Lacour S, Jacquin-Courtois S, Pisella L, Michel C, Revol P, Alahyane N, Luauté J, Gallagher S, Halligan P, Pélisson D, Rossetti Y (2015) Long-term sensorimotor and therapeutical effects of a mild regime of prism adaptation in spatial neglect. A double-blind RCT essay. Ann Phys Rehabil Med 58:40-53

Rode G, Pisella L, Petitet P, O'Shea J, Huchon L, Jacquin-Courtois S, Rossetti Y (2017) Quelles stratégies de rééducation dans la négligence spatiale unilatérale ? In: Roussel M, Godefroy O, de Boissezon X (eds) Troubles neurocognitifs vasculaires et post-AVC. De l'évaluation à la prise en charge. De Boeck Supérieur, Paris, pp 97-110

Rossi PW, Kheyfets S, Reding MJ (1990) Fresnel prisms improve visual perception in stroke patients with homonymous hemianopia or unilateral visual neglect. Neurology 40:1597-1599

Rossit S, Benwell CSY, Szymanek L, Learmonth G, McKernan-Ward L, Corrigan E, Muir K, Reeves I, Duncan G, Birschel P, Roberts M, Livingstone K, Jackson H, Castle P, Harvey M 
(2017) Efficacy of home-based visuomotor feedback training in stroke patients with chronic hemispatial neglect. Neuropsychol Rehabil 23:1-20

Roth T, Sokolov AN, Mesias A, Roth P, Weller M, Trauettel-Klosinski S (2009) Comparing explorative saccade and flicker training in hemianopia: a randomized controlled study. Neurology 72:324-331

Rowe F, Brand D, Jackson CA, Price A, Walker L, Harrison S et al (2009) Visual impairment following stroke: do stroke patients require vision assessment? Age Ageing 38(2):188-193

Rowe FJ, Conroy EJ, Bedson E, Cwiklinski E, Drummond A, Garcia-Finana M, Howard C, Pollock A, Shipman T, Dodridge C, MacIntosh C, Johnson S, Noonan C, Barton G, Sackley C (2016) A pilot randomized controlled trial comparing effectiveness of prism glasses, visual search training and standard care in hemianopia. Acta Neurol Scand 2017(136):310-321

Schaadt AK, Kerkhoff G (2016) Vision and visual processing deficits. In: Husain M, Schott J (eds) Oxford textbook of cognitive neurology \& dementia. Oxford University Press, Oxford, pp $147-160$

Schaadt AK, Schmidt L, Reinhart S, Adams M, Garbacenkaite R, Leonhardt E, Kuhn C, Kerkhoff G (2013) Perceptual relearning of binocular fusion and stereoacuity after brain injury. Neurorehabil Neural Repair 28(5):462-471

Schaadt AK, Schmidt L, Kuhn C, Summ M, Adams M, Garbacenkaite R, Leonhardt E, Reinhart S, Kerkhoff G (2014) Perceptual relearning of binocular fusion after hypoxic brain damage: four controlled single-case treatment studies. Neuropsychology 28(3):382-387

Schindler I, Kerkhoff G, Karnath H-O, Keller I, Goldenberg G (2002) Neck muscle vibration induces lasting recovery in spatial neglect. J Neurol Neurosurg Psychiatry 73:412-419

Schmidt L, Keller I, Artinger F, Stumpf O, Kerkhoff G (2013a) Galvanic vestibular stimulation improves arm position sense in spatial neglect: a sham-stimulation-controlled study. Neurorehabil Neural Repair 27:497-506

Schmidt L, Utz KS, Depper L et al (2013b) Now you feel both: galvanic vestibular stimulation induces lasting improvements in the rehabilitation of chronic tactile extinction. Front Hum Neurosci 7:90

Schreiber A, Vonthein R, Reinhard J, Trauzettel-Klosinski S, Connert C, Schiefer U (2006) Effect of visual restitution training on absolute homonymous scotomas. Neurology 67:143-145

Schröder A, Wist ER, Hömberg V (2008) TENS and optokinetic stimulation in neglect therapy after cerebrovascular accident: a randomized controlled study. Eur J Neurol 15:922-927

Schuett S (2009) The rehabilitation of hemianopic dyslexia. Nat Rev Neurol 5:427-437

Schuett S, Heywood C, Kentridge W, Zihl J (2008) Rehabilitation of hemianopic alexia: are words necessary for relearning oculomotor control? Brain 131:3156-3168

Smit M, Schutter DJLG, Nijboer TCW, Visser-Meily JMA, Kappelle LJ, Kant N, Penninx J, Dijkerman HC (2015) Transcranial direct current stimulation to the parietal cortex in hemispatial neglect: a feasibility study. Neuropsychologia 74:152-161

Spitzyna GA, Wise RJ, McDonald SA, Plant GT, Kidd D, Crewes H et al (2007) Optokinetic therapy improves text reading in patients with hemianopic alexia: a controlled trial. Neurology 68(22):1922-1930

Suchoff IB, Kapoor N, Ciuffreda KJ, Rutner D, Han E, Craig S (2008) The frequency of occurrence, types, and characteristics of visual field defects in acquired brain injury: a retrospective analysis. Optometry 79(5):259-265

Thieme H, Mehrholz J, Pohl M, Behrens J, Dohle C (2013) Mirror therapy for improving motor function after stroke. Stroke 44:e1-e2

Trauzettel-Klosinski S (2011) Current methods of visual rehabilitation. Deutsches Ärzteblatt International (English) 108:871-878

Turgut N, Miranda M, Kastrup A, Eling P, Hildebrandt H (2018) tDCS combined with optokinetic drift reduces egocentric neglect in severely impaired post-acute patients. Neuropsychol Rehabil 28(4):515-526

Van Wyk A, Eksteen CA, Rheeder P (2014) The effect of visual scanning exercises integrated into physiotherapy in patients with unilateral spatial neglect poststroke: a matched-pair randomized control trial. Neurorehabil Neural Repair 28:856-873 
WHO (2001) International classification of functioning, disability and health. World Health Organization, Geneva.

Wilkinson D, Zubko O, Sakel M, Coulton S, Higgins T, Pullicino P (2014) Galvanic vestibular stimulation in hemi-spatial neglect. Front Integr Neurosci 8:4

Wilson B, Cockburn J, Halligan P (1987) Development of a behavioral test of visuospatial neglect. Arch Phys Med Rehabil 68:98-102

Yang NYH, Zhou D, Chnung RCK, Li-Tsang CWP, Fong KNK (2013) Rehabilitation interventions for unilateral neglect after stroke: a systematic review from 1997 through 2012. Front Hum Neurosci 7:1-11

Zhang X, Kedar S, Lynn JJ, Newman NJ, Viousse V (2006) Natural history of homonymous hemianopia. Neurology 66:901-905

Zihl J (1995) Eye movement patterns in hemianopic dyslexia. Brain 118:891-912

Zihl J (2011) Rehabilitation of visual disorders after brain injury, 2nd edn. Psychology Press, New York

Zihl J, Kerkhoff G (1990) Foveal photopic and scotopic adaptation in patients with brain damage. Clin Vis Sci 2:185-195

Open Access This chapter is licensed under the terms of the Creative Commons AttributionNonCommercial-NoDerivatives 4.0 International License (http://creativecommons.org/ licenses/by-nc-nd/4.0/), which permits any noncommercial use, sharing, distribution and reproduction in any medium or format, as long as you give appropriate credit to the original author(s) and the source, provide a link to the Creative Commons license and indicate if you modified the licensed material. You do not have permission under this license to share adapted material derived from this chapter or parts of it.

The images or other third party material in this chapter are included in the chapter's Creative Commons license, unless indicated otherwise in a credit line to the material. If material is not included in the chapter's Creative Commons license and your intended use is not permitted by statutory regulation or exceeds the permitted use, you will need to obtain permission directly from the copyright holder.

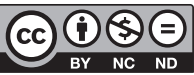

